\title{
SCIDOC
}

International Journal of Dentistry and Oral Science (IJDOS)

ISSN: $2377-8075$

\section{Surface Morphology And Corrosion Resistance Of Preformed Stainless Steel Crowns Evaluated Using Scanning Electron Microscopy (SEM) - An In Vitro Study}

Research Article

S Sushanthi ${ }^{1}$, S.S.Raj ${ }^{*}$, Meignana Arumugham Indiran ${ }^{3}$

${ }^{1}$ Post-Graduate Student, Department of Public Health Dentistry, Saveetha Dental College \& Hospital, 162, Poonamallee High Road, Chennai-600077, India.

${ }^{2}$ Reader, Department of Public Health Dentistry, Saveetha Dental College \& Hospital, 162, Poonamallee High Road, Chennai-600077, India.

${ }^{3}$ Professor and Academic Head, Department of Public Health Dentistry, Saveetha Dental College \& Hospital, 162, Poonamallee High Road, Chennai-600077, India.

\section{Abstract}

\begin{abstract}
The paper deals with the corrosion behaviour and surface morphology of two commercial brands of crowns named 3M crowns and Kids crown using Scanning electron microscope (SEM). Ten stainless steel crowns of the first primary mandibular molar of size 6 of two commercial brands named Kids crown (Shinhung, Seoul, Korea) and 3M Stainless Steel Primary Molar Crowns(3M ESPE, St. Paul, MN, USA) were used in the study. Surface morphology was analyzed using SEM measuring 20 $\times 20$ microns and at a magnification of 4000x and corrosion resistance was analyzed using anode polarization test. Visual examinations of exposed surfaces were performed and metallographic sections of U-bend specimens were carried out in order to assess stress corrosion cracking. From the study results, Kids crown was comparatively better than $3 \mathrm{M}$ crowns on testing for surface morphology and Corrosion resistance. Further antimicrobial tests and wear resistance should be tested for finalizing the study results.
\end{abstract}

Keywords: Corrosion; Surface Morphology; Scanning Electron Microscope; Stainless Steel; Crowns.

\section{Introduction}

Most common problems in pediatric dentistry are the early childhood caries of deciduous teeth that affect infants and young children [1]. Presence of one or more decayed (non-cavitated or cavitated lesions), missing (due to caries) or filled tooth surfaces in any primary tooth in a preschool-age child between birth and 71 months of age is defined as Early childhood caries. This type of caries leads to structural disintegration of the deciduous teeth in relation with definite nutritional problems or deficiency [2]. Most familiar way to repair the carious teeth and to maintain the restored teeth from damaging again is using Stainless steel crowns $[3,4]$.

Prefabricated SS crowns (SSCs) have been used in dentistry to restore primary and permanent teeth for almost 50 years [5]. Stainless steel crowns have been used till date due to its superior property of better retention and less recurrent caries. The blend of iron, carbon, chromium and other metals that make up stainless steel prevents corrosion otherwise exacerbated by saliva. Chrome is the main element that helps to prevent from the oxidation reaction. They are highly recommended due to its durability and its protective effect caused by the full coverage of the teeth but do not have a natural tooth color and are primarily used on molar teeth for aesthetic reasons [6].

Apart from its several advantages SSCs also have notable disadvantages like its potential allergenicity and inadequate fitness of the edges of the crown with tooth and inadequate retention in severely damaged teeth, especially on the buccal and lingual surfaces $[7,8]$. Although these mentioned limitations do not have a major impact on the patient satisfaction rate and SSCs do not exhibit serious damage on adjacent gingiva and underlying bone [1].

Resistance to penetration or permanent indentation of the surface is defined as hardness [9]. The term of wear can easily be defined as the process of removing material from the surface when two surfaces are rubbed together. When SSCs were used

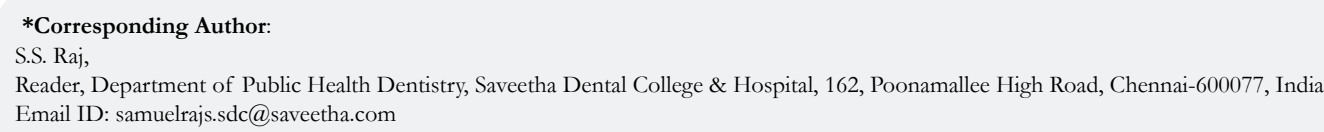

Copyright: S.S.Raj 2021 . This is an open-access article distributed under the terms of the Creative Commons Attribution License, which permits unrestricted use, distribution and reproduction in any medium, provided the original author and source are credited. 
in children with bruxism who have high chewing forces show a lot of wear in the occlusal surface of the crown and even can be pierced due to prolonged use in the mouth. Occlusal wear is the main cause of occlusal surface perforation and SSC failure. One of the problems that may occur for the SSCs is galvanic corrosion following contact with dental amalgam, which is due to presence of metal in both of them.

Corrosion of iron is a combination of dual and rather complex oxidation-reduction processes involving cascades of electron releases. Corrosion is a huge problem in dental hygiene and maintenance of the mechanical integrity of metallic implants.he unique mechanical properties of stainless steels coupled with their heat and corrosion-resistance and their low maintenance have made them durable and superior crown materials over amalgam and other common dental crown restorative materials [10]. The electrochemical corrosion phenomenon occurs in the oral cavity, resulting in degradation of the alloy as a result of enzyme activity, microbes, heat and chewing corrosion causes release of metals $[11,12]$. Many studies have shown that stainless steel alloys in the vicinity of saliva exhibit corrosion and alteration of surface properties, and thus their biocompatibility is reduced and releases metallic ions like $\mathrm{Cr}, \mathrm{Fe}$, and $\mathrm{Ni}$ [13]. The aim of the study is to compare the effectiveness of surface morphology and corrosion resistance of two commercial brands of Stainless steel crowns using Scanning electron microscopy(SEM).

\section{Materials And Methods}

This in vitro study was carried out at the Dental Materials Research Lab of Saveetha Institute of Medical and Technical Sciences in November 2020. Ten stainless steel crowns of the first primary mandibular molar of size 6 of two commercial brands named Kids crown(Shinhung, Seoul, Korea) and 3M Stainless Steel Primary Molar Crowns(3M ESPE, St. Paul, MN, USA) were used in the study.

\section{Surface morphology}

During the process of laser heating of metal surfaces, oxidation reactions of part of the metallic alloy components occur in the surface layer. The oxide layer may vary as to the chemical composition, thickness, continuity and adhesion to the substrate depending on the laser power (fluence) and the generated temperature. All changes will significantly affect corrosion resistance of the layer. It was analyzed using Scanning electron microscopy measuring $20 \times 20$ microns and at a magnification of $4000 x$.

\section{Corrosion test (electrochemical test)}

The anodic polarization tests were done using a conventional three-electrode cell of $250 \mathrm{ml}$ capacity. This cell was fitted with a saturated calomel electrode (SCE), work electrode as the reference electrode and a platinum sheet as the counter electrode. The ion implanted and virgin samples were each used in turn as the work electrode. The standard cyclic anode polarization test was performed in an electrolyte solution of $\mathrm{NaCl}\left(9 \mathrm{~g} / 1\right.$ of $\left.\mathrm{H}_{2} 0\right)$ at $\mathrm{pH}$ 6.3 at the temperature of $37^{\circ} \mathrm{C}$. This solution imitates the natural tissue environment. After 3600 s of immersion in $\mathrm{NaCl}$ solution, when a good stable potential could be attained, the potentiodynamic polarization test was done at a scan rate of $100 \mathrm{mV} / \mathrm{s}$. The contact area in all cases was $0.1956 \mathrm{~cm}^{2}$. The scan was started in the anode direction with a scanning rate of $100 \mathrm{mV} / \mathrm{s}$. After the corrosion tests were ended for both the treated and virgin materials of AISI 316L SS, the corrosion current density (icorr), corrosion potentials (Ecorr) and pitting potential (Epit) were by linear fit.

\section{Assessment of Microhardness}

The total of 10 stainless steel crowns from each brand was placed on a Vickers microhardness Tester under a load of $200 \mathrm{~g}$ for 15 seconds. The crowns were placed horizontally to provide the best possible smooth level for the indenter. After placing the specimen under the microscope, the effect of indentor on the specimen was measured. After applying the force, the created effect was measured with a magnification of $\times 20$. Given the diameter and depth of the effect, the hardness number of the specimen was calculated by the machine. For each specimen, the hardness was measured at 3 points at the mesial area and the average was reported.

\section{Results}

\section{Surface morphology}

Defect on the surface was analysed using Scanning electron microscopy. No cracking was seen, only micro defects were seen.

The surfaces of corroded samples were analyzed by scanning electron microscopes (SEM). The morphological analysis carried out in the surface of the corroded samples shows the pits in the surface. The analysis of the morphological images of corroded samples is in agreement with the electrochemical test results for both Kids crown and 3M crowns. Comparatively Kids crowns have good surface morphology.

\section{Corrosion behaviour}

Quantitative assessment of corrosion has been conducted by potentiodynamic polarization tests. Tafel analysis is a well-established electrochemical technique [14] in which a typical potential scan of $\pm 25 \mathrm{mV}$ around the open circuit voltage is imposed on a

Figure 1. SEM image of surface morphology of $3 \mathrm{M}$ crowns.

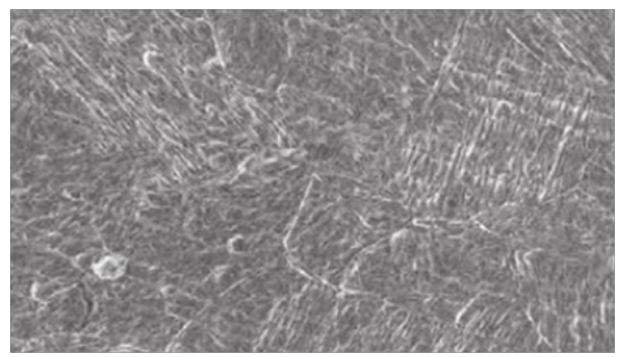


Figure 2. SEM image of surface morphology of Kids crowns.

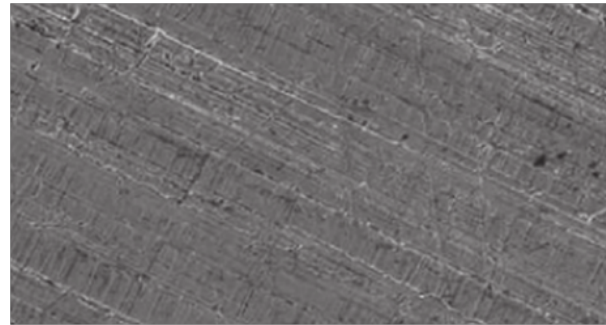

Figure 3. SEM image of micro defect on Stainless steel crowns.

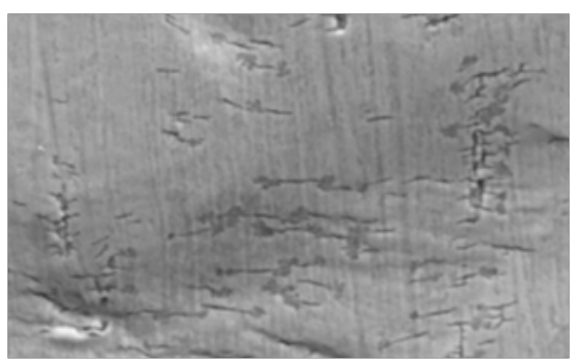

metal sample and the current value obtained was recorded.

Basically two regions are present in anodic polarization curves, first region represents the dissolution of the included Stainless steel crowns which was kinetically limited and the anodic current was increased slowly with the potential showing a "passive-like" behavior. Finally, there is a transpassive second region starting at a critical potential (Epit), where the rapid increase in the current value occurs due to breakdown of the passive film. This phenomenon is commonly known as pitting corrosion.

Visual examinations of exposed surfaces were performed and metallographic sections of U-bend specimens were carried out in order to assess stress corrosion cracking.

\section{Discussion}

Surface morphology was analysed using Scanning electron microscopy (SEM) $20 \times 20$ microns and at a magnification of 4000x. Overall no cracks were found, only micro defects were seen.

These results were in accordance with corrosion resistance. Comparatively Kids crowns were better than $3 \mathrm{M}$ crowns.

Corrosion resistance was analyzed using anodic polarization tests. The studied crowns had significant different physical and mechanical properties. In this study the highest corrosion potential was observed in Kids Crown $>3 \mathrm{M}$ crowns respectively. This is in accordance with study results conducted by Eliadas T er al., [15]. Corrosion leads to surface roughness and the release of elements from metal or alloy. Releasing of elements causes color changes of the adjacent soft tissue and development of allergic reactions in sensitive individuals.

Corrosion resistance plays a very vital role in regulating the possibility of using metal alloys as biological materials. The effect of molybdenum on pitting corrosion resistance in stainless steel austenitic alloys was conducted by $\mathrm{Ha}$ et al [16]. In the mouth, the crowns are immersed in the saliva, which acts as an electrolyte and causes corrosion. According to Eliades et al, the acidic and chloride conditions may lead to the destruction of the chromium oxide layer.

Acids can include plaque acids and acids in foods. Nowadays, crowns containing $72 \%$ of nickel are replaced with SSCs containing $8-10 \%$ nickel, because of the several reports about the role of nickel ions in allergic, toxic or carcinogenic effects. Stainless steel alloy based on iron-chromium-nickel has favorite mechanical properties and suitable corrosion resistance. Although there is always a passive layer on the surface of the alloy, various ions can be released from the metal surface in the acidic environment of the mouth and causes a corrosion phenomenon.

\section{Conclusion}

From the study results, Kids crown was comparatively better than $3 \mathrm{M}$ crowns on testing for surface morphology and Corrosion resistance. Further antimicrobial tests and wear resistance should be tested for finalizing the study results. Future studies can be done with more samples.

\section{References}

[1]. Bamdadian Z, Pasdar N, Alhavaz A, Ghasemi S, Bijani A. Comparative Evaluation of Physical and Mechanical Properties of Different Brands of Primary Molar Stainless-Steel Crowns: An In Vitro Study. Open Access Maced J Med Sci. 2019 Dec 15;7(23):4120-6.PubmedPMID: 32165963.

[2]. Santamaria RM, Innes NPT, Machiulskiene V, Evans DJP, Alkilzy M, Splieth $\mathrm{CH}$. Acceptability of different caries management methods for primary molars in a RCT. Int J Paediatr Dent. 2015 Jan;25(1):9-17.PubmedPMID: 24602167.

[3]. Seale NS. The use of stainless steel crowns. Pediatr Dent. 2002 Sep;24(5):501-5.

[4]. Pathak S, Shashibhushan KK, Poornima P, Reddy VS. In vitro Evaluation of Stainless Steel Crowns cemented with Resin-modified Glass Ionomer and Two New Self-adhesive Resin Cements. Int J ClinPediatr Dent. 2016 Jul;9(3):197-200.PubmedPMID: 27843249.

[5]. Yilmaz Y, Kara NB, Yilmaz A, Sahin H. Wear and repair of stainless steel crowns. Eur J Paediatr Dent. 2011 Mar;12(1):25-30.Pubmed PMID: 21434732.

[6]. Abdulhadi B, Abdullah M, Alaki S, Alamoudi N, Attar M. Clinical evaluation between zirconia crowns and stainless steel crowns in primary molars teeth. J ClinPediatr Dent. 2017;5:21.

[7]. Garg V, Panda A, Shah J, Panchal P. Crowns in pediatric dentistry: A review. Journal of Advanced Medical and Dental Sciences Research. 2016;4(2):41.

[8]. Randall RC. Preformed metal crowns for primary and permanent molar 
teeth: review of the literature. Pediatr Dent. 2002 Sep;24(5):489-500.Pubmed PMID: 12412964.

[9]. Alavi S, Kachuie M. Assessment of the hardness of different orthodontic wires and brackets produced by metal injection molding and conventional methods. Dent Res J . 2017 Jul;14(4):282-7.Pubmed PMID: 28928783.

[10]. Sharaf AA, Farsi NM. A clinical and radiographic evaluation of stainless steel crowns for primary molars. Journal of dentistry. 2004 Jan 1;32(1):27-33.

[11]. Ramazani N, Ahmadi R, Darijani M. Assessment of nickel release from stainless steel crowns. J Dent . 2014 May;11(3):328-34.PubmedPMID: 25628668.

[12]. Kubala E, Strzelecka P, Grzegocka M, Lietz-Kijak D, Gronwald H, Skomro P, et al. A Review of Selected Studies That Determine the Physical and Chemical Properties of Saliva in the Field of Dental Treatment. Biomed Res Int. 2018 May 9;2018:6572381.Pubmed PMID: 29854777.
[13]. Saporeti MP, Mazzieiro ET, Sales WF. In vitro corrosion of metallic orthodontic brackets: influence of artificial saliva with and without fluorides. Dental Press J Orthod. 2012;17(6):24e1-24e7.

[14]. Zaveri N, Mahapatra M, Deceuster A, Peng Y, Li L, Zhou A. Corrosion resistance of pulsed laser-treated Ti-6Al-4V implant in simulated biofluids. electrochimicaActa. 2008 Jun 1;53(15):5022-32.

[15]. Eliades T, Athanasiou AE. In vivo aging of orthodontic alloys: implications for corrosion potential, nickel release, and biocompatibility. Angle Orthod. 2002 Jun;72(3):222-37.Pubmed PMID: 12071606.

[16]. Ha H-Y, Lee T-H, Bae J-H, Chun DW. Molybdenum Effects on Pitting Corrosion Resistance of FeCrMnMoNC Austenitic Stainless Steels. Metals. 2018 Aug 20;8(8):653. 